\title{
The Correlation between the Personal and Family Characteristics of Saudi Youth and the Inclination towards Extremism
}

\author{
Benayeh Mohammed Saud Al Rasheed \\ Social Work Assistant Professor \\ College of Art - Department of Social Studies \\ King Saud University \\ Riyadh - Saudi Arabia
}

\begin{abstract}
This study aims to define the correlation between the personal and family characteristics of Saudi youth and the inclination towards extremism. This analytical study was implemented on students at King Saud University, and the study tools consisted of a questionnaire that was divided into two parts: the first part contained basic information, while the second part contained 38 sentences. The sample was 300 students from humanities and science faculties. Before the researcher started measuring, she confirmed the slope of variables in the measurement, which were the inclination towards extremism, family characteristics, and personal characteristics. The natural distributions showed that the three variables were naturally distributed. The researcher also used a one-way ANOVA analysis when analyzing the results of the demographics of parents and the youth's inclination towards extremism. As for the family characteristics and personal characteristics variables, the researcher used Pearson's correlation coefficient, where the results showed that there is no significant correlation between the family characteristics and the youth's inclination towards extremism, while the results of the personal characteristics variable showed that there is a significant correlation between personal characteristics and youth's inclination towards extremism.
\end{abstract}

Keywords: characteristics, family characteristics, personal characteristics, youth, inclination, extremism

\section{Introduction}

Extremism is considered one of the main issues that concern many contemporary societies, and many researchers claim that the phenomenon of extremism was not born in this age, rather it is as old as humans but it has prevailed; to emerge from the scope of individual cases and become one of the distinctive social phenomena of this age with the diversity of cultures and societies.

The youth are among the most susceptible groups to extremism in behavior, duo to the known psychological and social characteristics of this age. Forms of extremist inclinations have spread among the youth, especially university youth, the most obvious of which were the inclination of some individuals towards isolation and negativity, while others followed extremist behavior inclinations that extended to using violence and terrorism. These inclinations reflect a youth culture that is characterized by rejection of norms, values, and authority exercised by adults in society, to the extent where the characteristic of rejection became a common public position that is clearly manifested in numerous situations and different societies.

Some western writings describe the youth culture as a lifestyle that is independent from the world of adults, which is not subject to the norms and values of seniors, as well as their beliefs and behaviors, rather a lifestyle based on a system of values, norms, thoughts, and non-committed behavioral methods. Therefore, the youth culture is a type of special language, values and behaviors that are characterized by the spirit of rebelliousness and stubbornness towards adults, thus transforming this culture into a functional culture that may not serve the constructive process sought by society, turning into adopting counter thoughts that express challenge against values and norms that the society desires for itself. (Al Sayyed, 1990).

\subsection{The Statement of Problem}

Extremism has manifested into a reality in many contemporary societies, and while it is not a new issue, it has become a global phenomenon. On other words, it is not linked to a particular region, culture, society, religion, or ethnicity.it is linked to social, cultural, political, and technological factors that have been created by the rapid and progressive developments of the modern age. The early years of the 21 st century saw a dramatic increase in terrorist operations, the most severe of which were the events of September 11. 
Indeed, terrorism was not confined only to western countries, but also to Arab countries including Saudi Arabia where they suffered from terrorist attacks that targeted residential complexes, government institutions, killings and kidnappings of foreigners. It gets even more puzzling when girls join organizations such as ISIS or similar ones, or when they sympathize with such organizations, all of which reflect a radical ideology among the youth,(Al Yousef, 2005).

This study is an attempt to review the correlation between some personal and family characteristics and the youth's inclination towards extremism. The family carries a great responsibility in looking after and shielding its children from any ideological deviance, because that leads to fundamentalism and extremism, and that is done by watching its children without raising their suspicion, especially in light of this invasion and live media broadcasting that strives to destroy all their values and principles. So, the family is not only responsible for providing the necessities and living supply of food and drink to its members and keeping them safe; however, it is also required to cooperate with other community institutions to keep the peace, and it must have a proactive and preventative role through interactive relationships with the other community institutions, to overcome the problems and try to contribute to solving them. Thus, the family has to work on finding an effective role for it among those institutions. While the negligence or failure of the family in achieving upbringing and guidance of its children that they need and is dictated by religion may lead to the children's deviation.

Therefore, families today are more required than ever before to cooperate with the other community institutions (schools, mosques, media, security, and advocacy institutions) on forming the right concepts, values, and ideals, as well as creating a strong, tight relationship between families and those institutions, and enhance intellectual security and social values in the minds of their children so they become a protective shield against the abduction of the children's minds. The negligence of families in looking after their children may also cause numerous abnormal behaviors, such as running from school, homelessness, carelessness and irresponsibility, falling victim for drugs, delinquency, solitude and isolation. Those who follow the stories of terrorists told by their close associates find out that they were introverted and isolated from society, making it easy to deceive them. (Al Rumih, 2015)

From the above, the problem of the current study is determined as follows: the correlation between the personal and family characteristics of Saudi youth and the inclination towards extremism.

\subsection{Study Significance}

The significance of this study shows in that extremism is the topic of the hour, and it is considered one of the most dangerous, impactful, and research-worthy topics; Muslims today are facing problems, challenges, and survival battles. In addition, extremism has many dangers that affect individuals and groups, the construction of society, and development goals. Therefore, studying the connection between extremism and personal and family characteristics is an issue of great importance in order to outline its causes, how to protect against it, and how to confront and treat it.

The significance of the study also lies in figuring out the personal and family characteristics that may be some of the reasons that make young people extremists who adopt terrorist operations. Undoubtedly, national security has become not only the responsibility of police officers, rather an issue that all official and unofficial community institutions should engage in, most importantly the family.

The significance of the study is also presented in how much results it yields to help those in charge of caring for, educating, and upbringing of youth with setting plans and preventive programs, in order to help them meet their needs as much as possible, and to guide educational programs makers and planners with introducing pedagogical education plans that in turn help meet the needs of youth. Also, the results will help university departments set up plans and preventative programs in the context of guidance and education to deal with students, as well as helping civil community institutions increase cultural and social programs and events to engage the youth in the community, as they are a very important part of society.

\subsection{Study Objectives}

This study aims to answer the following hypotheses:

1. There is a correlation between the demographic characteristics of the father and youth's inclination towards extremism.

2. There is a correlation between the demographic characteristics of the mother and the youth's inclination towards extremism.

3. There is a correlation between the family characteristics and the youth's inclination towards extremism.

4. There is a correlation between the personal characteristics of youth and their inclination towards extremism.

\subsection{Definitions in the study}


Characteristics: which is the plural of a characteristic and it is the quality that differentiates and defines something, and characteristics are features and qualities that differentiate something from other things. Lexically, the definition of 'characteristics' revolves around "individuals, favor, and distinction."

Contextually, the definition of characteristics is: the things that make something or someone unique (Al FairouzBadi, 2005). Allport defines character as the dynamic organizing that lies within the individual, which regulates the psychosocial systems that determine the nature of his/her behavior and thinking. (Allport, 1961)

Personal characteristics: are a "reflection of the relative consistency of behavior for many situations," as well as "a constant willingness or inclination towards a particular type of behavior." Personal traits are the correspondence of a set of aspects to show a certain behavior. Each person has unique characteristics that distinguish them from others, and they depend on genetic and physical factors as well as environmental and educational factors, all of which depend on the degree of interrelationship between all factors, including cognitive characteristics (intelligence, motor skills, general knowledge), emotional and reactive characteristics (mood, emotional stability), realistic characteristics (desires, tendencies, attitudes, and emotions), and social characteristics (sensitivity to social problems, participation in social events),(Atkinson, 2000).

Procedural definition: the personal characteristics of this study are: physical and mental psychological characteristics of students in the Saudi society, which form their values, attitudes, thoughts, and opinions towards extremism.

Family characteristics: the family is a primary group whose members have certain obligations and live in common housing. The American society of social workers defines family as: two or more individuals who consider themselves family and impose obligations, functions, and basic general responsibilities;for the family to live together, (Barker, 2003).

Al Dakheel(2006) defines family as: a biological, psychological and cultural group, not limited to other groups, with a special structure, needs and living conditions, which in itself constitutes a social psychological refuge for its members, and its internal and external activities offer the smallest model of a partial society. The family is the first social unit that aims to preserve the human kind, and is based on the requirements that are accepted by the common mind, and the rules that the different societies determine,(Al Dakheel, 2006).

The family is as any social group with functions, goals, and standards that govern the relationship between its members, its leadership, the duties of its members, and the rights they receive. The characteristics are the signs that distinguish a family from other groups in society,(Mursi, 2008).

Procedural definition: what is meant by family characteristics in this study are the traits or qualities that differentiate a family from other families, and protect its members from youth extremism.

Youth:Young adults are individuals between the ages of 18 and 24 years, which are those who have completed general schooling. This age is characterized by being a transitional phase to masculinity or motherhood. Young adults skip guidance and caring phases and are more liberal; this stage requires particular treatment,(Al Dakheel, 2006).The specific criteria for defining the age range for young adults vary among countries and organizations around the world. For example:

1. The United Nations defines the youth age as those between the ages of 15 and 24 years. (United Nations, 2007)

2. Al Munjid glossary of modern Arabic language defines this age between puberty and 30 years of age. (Omar \& Abdul Baqi, 1988)

Procedural definition: Young adults in this study are students between the ages of 19 and 24 years who are studying in the bachelor's degree (science and humanities) at King Saud University in Riyadh at the time of this study.

Attitude: Attitude is defined as "a feeling of a state of mental readiness, whether positive or negative, acquired and organized through experience, which causes a certain impact on the individual's response to people and objects." Attitudes cannot be seen, but they are inferred, as they are a coherent organization of concepts, beliefs, traditions, and motives for something in particular. This does not mean that personal characteristics have no function, but they are part of the attitudes, and they integrate and interact with motives to establish the individual's attitudes and tendencies towards certain things. (Abdelaziz, 2013).Attitude is also defined as: mental readiness, tendency to act, or a reaction of some sort. It is often used as a synonym for opinion in informal language, which is synonymous with the term "challenge.", (Barker, 2003)

The procedural definition of the youth's attitude towards extremism is: the outcome of respondents' answers to the issue of extremism in terms of support or opposition. By applying the measure of attitude towards extremism, the level of individuals' inclination towards extremism is estimated (negative or positive). 
Positive attitudes are when obtaining a high score on their answers to the terms of the scale prepared by the researcher, and negative attitudes are when individuals score low on their answers to the terms of the scale.

Extremism: The Arabic language dictionary defines extremism as: political, religious, sectarian or intellectual extremism, a dangerous, destructive approach to individuals or groups.

"Some countries make strenuous efforts to eliminate terrorist extremism.", (Omar, 2008).Lexically, extremism is defined as standing on edge, which is the end of an object, and can be used for objects, time, and others. Contextually, extremism is defined as: beyond the limit of moderation. The relationship between the two definitions is clear, as everything has a middle and two edges. When someone exceeds the middle towards one side then they are "extreme." Extremism can be the fabric of a particular ideology, or mixture of rigid beliefs, or the views of a particular group.

So if they adopt the ideology then they are extreme, and the group member is an extremist, and one cannot abandon their extremism unless the ideology is discussed freely and positively where the group can see the bad intentions, actions, and consequences, (Al FairouzBadi, 2005).Webster's dictionary suggests that extremism is moving away from what is logical, reasonable, or acceptable like fundamentalism. Extreme refers to any two areas that are contradictory and far apart, such as pain and pleasure,(Webster, 1984).

To sum up; extremism is the rigid method of thinking, and intellectual closure of an individual or group of society, which is exceeding the level of moderation in behavior and belief in a way that makes the individual believe that they are the only one with the right opinion, and sees that others must abide by what he thinks or believes,(Najm, 2013).

Procedural definition: In this study, what is meant by extremism is: any ideology that leads to a behavior aimed at spreading terror or forcing opinions. Corruption and destruction are all forms of terrorism, violence, and extremism. Disturbing the peace and causing chaos in stable societies is a modern form of terrorism, violence, and extremism, which grows with the spread of fundamentalist ideas that aim to execute others, and impose ideas by force and under the threat of weapons. However, these ideas are not limited to a specific time or place, rather the whole world has become a theatre for them.

\section{Theoretical framework}

According to modern psychology, young adulthood is a transitional phase that comes between adolescence and adulthood; therefore it has its own characteristics that differentiate it from other phases. Perhaps some of its most important characteristics are emotional contradiction of self and social inclusion. Teenagers often accept society's definitions of being hesitant or compliant, lazy or energetic. However, during young adulthood, the relationship between those traits defined by society and the true self of youth becomes an issue that causes many problems.

Awareness of possible or realistic conflicts is rapidly heightened by the lack of harmony and congruence between the youth's perception of their true selves and the resources and requirements of the existing society. How to achieve harmony and congruence between those two scenarios will always be one of the most important issues faced by young people,(Morris, 1982).

During young adulthood, there also may be feelings of alienation and clear rejection of socialization and cultural urbanization processes, where young people feel the depth of the influence of society and culture on their personality. Sometimes they try to abandon their roles acquired from their cultures and history (past experiences) and look for other roles that tend to confirm the change, transformation, and movement, and hate everything that is static and constant. Change and movement are the basis of youth's feeling of vitality and positivity to overcome their sense of freedom deprivation, or feeling that they are confined within a specific frame or boundaries.

Those suicide attempts among young people are only a reflection of their frustration, and their feeling of endless helplessness, or failure to achieve this expression. Also, some young people tend to come together to form and build a so-called "counter culture" or youth, which is a pattern or a cultural solidarity characterized by deliberate detachment, and culturally meant by the existing social order, whether it takes the form of small groups or official organizations. This counter culture is not characterized by youthful consciousness, but rather a distinct lifestyle for a particular group, (Erikson, 1963).

The researcher based her interpretations of the problem of the study on the theories of psychology and sociology. Sigmund Freud, a pioneer and founder of the school of psychoanalysis, believes that man is a creature of a biological nature and that his main motivation is to satisfy the internal physical and sexual needs. He is a creature that is forced to satisfy his instincts by all means and methods, where the personality is formed according to the psychoanalysis of the ID, which is the engine of instincts and everything inherited from birth. Seeking to satisfy the instinctive needs is the principle of pleasure, and consists of the Ego, dealing with reality to meet the individual's instinctive needs, and also consists of the Super-Ego,(Al Mushawah, 2007). 
Zaighor explains extremism and violence as: an aggressive behavior that stems from the instincts with which man are born, and are carried in his psychological formula. The instincts of death and life are also responsible for this. The instinct of death pushes man towards aggression, leading to suicide or violence and war, which leads individuals to violence, murder, and harming themselves and others.

A child who was despised and subjected to repression (self-hate) in their younger years forms a revengeful approach when dealing with others, which pushes them to seek "payback" by getting whoever humiliated or hurt them through "venting", which is emptying the self from oppression,(Zigor, 1986).

In spite of the many criticism of the theory of psychoanalysis, one cannot overlook its emphasis on several important things, such as calling for attention during the early years of a child's life, through which to draw the map of their future behavior. This map has the greatest impact on their formation of character and relationship to their parents and how they have a significant impact on shaping their behavior.

The learning theory denies that extremism is an instinctive behavior; it is acquired from the surrounding environment, especially in the early years of life, such as the family and school, where the individual gains extremist behavior through learning from others. If the father or role model were extremist, then the children are more prone to be affected and gain this behavior, especially if this extremist behavior was met with approbation rather than disapproval, as that may reinforce the persistence of this child's behavior. For example, take a father who praises his son for imposing his opinions on his colleagues and not listening to them. What can we expect from this child when he grows up?! Therefore, in the view of this hypothesis, the seeds of extremism arise since childhood from family and school, and are reinforced by societal reactions. We must not forget the role of worship and the impact it can have on the reinforcement of such behavior or not, (Al Zghool, 2003).

Therefore, the theory of social learning explains extremism as a learned behavior resulting from the individual's association with an extremist group so that the individual continues their criminal behavior; to feel a sense of belonging to the group. Also, the group supports this behavior so that the individual feels that he is one of its members who have a special common bond, which is extremist and deviant behavior.

\section{Previous Studies}

"The political, economic, and social variables related to the issue of terrorism", is a descriptive study prepared by Yousef (1995), it aims to identify the most important reasons that helped to form terrorist groups, including economic, social and family, and psychological factors. He then presented some phenomena of terrorist group behavior and some psychological and social characteristics. The results of the study found that there are some impacts on individuals that result from joining extremist group, in addition to the factors of success and expansion of terrorist groups and operations.

Another study prepared by Musa (2004) aimed to identify ideological deviance as a phenomenon that is widespread during these times. The study relied on the descriptive analytical method, and the results showed that ideological deviance is an inevitable result of the interaction of a number of social environmental factors, which leads the individual to adapt to deviant or extreme ideas, including those related to media, family, and educational institutions and their role in facing such extremist ideas.

Al Yousuf (2005) conducted a study about social patterns and their role in the fight against terrorism and extremism which aimed to the use of criminal behavior theories to explain terrorism and extremism while studying the social causes of the terrorism phenomenon and clarifying social patterns in combating terrorism, violence, and extremism. The results of the study revealed that the crime protection theories could be an appropriate input into how to activate the different social patterns to combat criminal behavior. The study also stressed the importance of activating the different social patterns (religious, family, media, economic, and security) in combating terrorism and extremism, and suggested a number of steps necessary to activate those patterns. The study concluded that the phenomenon of terrorism cannot be resisted through taking security measures alone, but there is an urgent need to activate the different social patterns and confirm the role of citizens in combating terrorism.

In addition ,AlShahrani (2006) implemented a study aimed to identify the role that the university can play in combating extremism through teaching, scientific research, and community service, and highlight the proposed solutions that faculty members believe would activate the role of universities in combating extremism. The study concluded many results, some of which are: the role that universities can play to combat extremism through teaching students the respect of others and other people's thoughts, the use of scientific research to know the causes of extremism to combat it and redirect it towards moderation in Islam, community service to prepare programs that attract students to benefit from their free time, and helping social institutions in making young people interact with the problems of society. 
Al-Qasimi (2010) prepared a study aimed to highlight the level of compatibility and difference between some theories of human behavior, with a focus on the integrative view of these theories in interpreting human behavior. The study also dealt with the issue of socialization and its role in shaping the behavior of the individual, and showed the ideal method for parents when dealing with children, taking into account how to achieve psychological compatibility and social adjustment as two basic dimensions of the children's mental health and formation of normal behavior.

Abu Al Ela(2010) implemented a study dealt with the history of terrorism, its classifications, characteristics and driving factors. The study also examined the types of terrorism and its effects, theories, and approaches that could be used with terrorism, and then clarified the proposed roles of community service in order to treat the phenomenon of terrorism.

Abu Diyya (2012), conducted a study examined the nature of inclination towards extremism in its religious, political, and social dimensions, and its relationship with the system of psychological needs (economic needs, the need to interact with others, the need to achieve and self-realization, the need to achieve social status, and the need for knowledge and culture). The results showed a significant correlation between extremism and non-satisfaction of psychological needs, indicating the need to satisfy the psychological needs of the individual in order to achieve a sense of satisfaction for themselves and their community. The results of the study showed that the need to achieve and selfrealize is the highest humanitarian needs of the Palestinian youth, and other psychological needs are only the appearance of those needs, and they all work to reach that end. That highlights the importance of the needs to achieve self-realization and its impact on the inclination towards extremism of university students, as the lack of satisfaction of the need to achieve self-realization is one of the most important causes that lead to the formation of extremist inclinations among university students.

To sum up; the previous studies presented above showed that there are multiple causes and factors that lead to extremism and terrorism. One of the reasons was the failure of families and educational institutions to play their role in protecting the members of society from extremism as mentioned in Musa's study (2004) and Al Yousuf's study (2006). Al Qasimi's study (2010) explained the issue of socialization and its role in forming the individual's behavior, and showed the ideal method for parents when treating their children. Some studies revealed the role of community service in combating terrorism among the youth as in the study of Abu Al Ela (2010). Another study showed the importance of satisfying the psychological needs of youth in the prevention of extremism, as in Abu Diyya's study (2012). This current study differs from the previous studies in identifying some personal and family characteristics of university youth and their relationship with the youth's inclination towards extremism.

\section{Method}

4.1.Type of study: this study is an analytical study that contributes to finding results by which any relationship through them can be accepted or rejected through the hypothesis studied in the society applied to the study, taking into account that the negation of the relationship does not mean that it is absent in the studied societies that researchers have reached through their previous studies.

4.2.Used method: the social survey method was used and is suitable for analytical studies. This approach is based on examining a set of items either by sample, or a comprehensive survey of all items of the study society to access specific information and data found in a certain society. (Al Dahyan\& Al Sabti, 2017)

4.3. Data collection tool: The researcher designed a questionnaire containing two parts:

The first part contains the initial data, while the second part contains simple and clear phrases. The researcher used the five-way Likert scale (strongly agree, agree, does not apply, disagree, strongly disagree) containing five values from 5-1 and consists of three dimensions:

1. The first dimension: phrases specific to the characteristics of the family of young people, consisting of 13 phrases.

2. The second dimension: phrases about the personal characteristics of youth, consisting of 11 phrases.

3. The third dimension: phrases about the youth's inclination towards extremism, consisting of 14 phrases.

4.4. Population of the Study: King Saud University students from all faculties and disciplines (science and humanities) in the second semester of the academic year 1438-1439 Hijri.

4.5. Sample of the Study: The sample consisted of a group of male and female students from King Saud University who registered for Islamic culture courses from the humanities and science departments. These courses were chosen because all students in all departments, faculties, and levels study these courses. 300 students were picked through the number of sections for these courses using a simple random sample. 
4.6.Variables of the Study:1-The independent variable: the inclination towards extremism. 2-Dependent variable: demographic characteristics of the father, demographic characteristics of the mother, family characteristics, and personal characteristics of youth.

\subsection{Limitations of the study}

-The human limitation: the study was applied to students from King Saud University in Riyadh, in all faculties (science and humanities) and from all disciplines.

-Location limitation: the study was applied at King Saud University in Riyadh (male and female students).

Time limitation: data were collected during the second semester of the academic year 2018.

\subsection{Sample Description}

Table (1) Occurrences of study sample by age

\begin{tabular}{|l|l|l|l|}
\hline Age & Occurrences & Percentage & Cumulative result \\
\hline From 21 to below 19 years of age & 107 & 38.8 & 38.9 \\
\hline From 21 to below 23 years of age & 141 & 51.1 & 90.2 \\
\hline From 23 to below 25 years of age & 24 & 8.7 & 98.9 \\
\hline Above 25 years of age & 3 & 1.1 & 100.0 \\
\hline Total & 275 & 99.6 & \\
\hline
\end{tabular}

Table(1) above indicates that most individuals of the study fall in the second category, from 21 to 23 years of age with 141 occurrences an a percentage of 51.5\%, also confirmed by the cumulative result of 90.2 for the first age category. The second age category of $28.9 \%$ and $51.1 \%$ in the second category. One can conclude from the results that the answers of the participants may be homogenous given the homogeneity of the age variable among the participants of the study.

Table (2) Occurrences of Study Sample by Discipline

\begin{tabular}{|l|l|l|l|}
\hline Discipline & Occurrences & Percentage & Cumulative result \\
\hline Humanities & 147 & 53.3 & 53.3 \\
\hline Scientific & 129 & 46.7 & 100.0 \\
\hline Total & 276 & 100.0 & \\
\hline
\end{tabular}

Table(2)above indicates the number of students in the faculty of humanities, which is 147 students with a percentage of $53.3 \%$, while the number of students in the science departments was 129 with a percentage of $46.7 \%$. This was expected because the number of students in the faculty of humanities is more than the number of students in the science faculties.

\section{Results}

The researcher used a one-way ANOVA analysis for the demographic characteristics of the father and the mother and their relationship with the youth's inclination towards extremism. The researcher also used Pearson's correlation coefficient for the personal characteristics variable and the youth's inclination towards inclination. Eventually, the researcher concluded the slope with the following results: First: the median and slope of age and discipline to show the homogeneity of the individuals of the sample among themselves.

Table (3)Median and Slope of Age and Discipline

\begin{tabular}{|l|l|l|}
\hline & Age & Discipline \\
\hline Number of individuals & 275 & 275 \\
\hline Median & 1.7 & 1.9 \\
\hline Slope & 0.66 & 0.99 \\
\hline
\end{tabular}

Table (3) above shows that the median and the slope of the age variable reached 0.66 and 9.99 for discipline, which indicates that the sample is highly homogenous

Question 1: Is there a relationship between the demographic characteristics of the father and the youth's inclination towards extremism? To answer this question a One-Way ANOVA analysis of the demographic characteristics of the father and the youth's inclination towards extremism is shown in Table (4). 
Table (4) One-Way ANOVA Analysis of the Demographic Characteristics of the Father and the Youth's Inclination Towards Extremism

\begin{tabular}{|l|l|l|l|l|l|}
\hline & $\begin{array}{l}\text { Total of } \\
\text { squares }\end{array}$ & $\begin{array}{l}\text { Degree of } \\
\text { freedom }\end{array}$ & Median of squares & F degree & Coefficient \\
\hline Among groups & 15.0 & 2 & 7.5 & 0.264 & 0.769 \\
\hline Inside groups & 658 & 231 & 28.5 & & \\
\hline Groups & 6613.9 & 233 & & & \\
\hline
\end{tabular}

The table above shows that father's education does not affect the formation of youth's inclination towards extremism, where the $\mathrm{F}$ degree is statistically insignificant, reaching 0.264 at coefficient 0.769 , which indicates that the educational level of the father has no effect on the youth's inclination towards extremism.

This may be a result, of the communication weakness between family members in light of the spread of social media and friends.

Question 2: Is there a correlation between the demographic characteristics of the mother and the youth's inclination towards extremism? To answer this question One-way ANOVA analysis of the demographic characteristics of the mother and the youth's inclination towards extremism was implemented .Table(5) shows the results .

Table (5) One-way ANOVA of the Demographic Characteristics of the Mother and the Youth's Inclination Towards Extremism

\begin{tabular}{|l|l|l|l|l|l|}
\hline & $\begin{array}{l}\text { Total of } \\
\text { squares }\end{array}$ & $\begin{array}{l}\text { Degree of } \\
\text { freedom }\end{array}$ & $\begin{array}{l}\text { Median of } \\
\text { squares }\end{array}$ & F degree & Coefficient \\
\hline Among groups & 0.81 & 4 & 0.204 & 1.42 & 0.226 \\
\hline Inside groups & 33.04 & 231 & 0.143 & & \\
\hline Groups & 33.857 & 235 & & & \\
\hline
\end{tabular}

Table (5) above shows that the education of the mother also does not affect the formation of the youth's inclination towards extremism, where the F degree is statistically insignificant, reaching 1.42 at coefficient 0.226 , which indicates that the educational level of the mother has no effect on the youth's inclination towards extremism. This may be a result, as mentioned before, of the communication weakness between family members in light of the spread of social media and friends. If the mother were more influential than the father, it may seem normal for the nature of communication between children and mothers. Before measuring, the slope of the variables involved in the measurement was confirmed, which are the inclination towards extremism, family characteristics, and personal characteristics. The values of the slope were presented in Table (6):

Table (6) Slope values

\begin{tabular}{|l|l|}
\hline Variable & Slope value \\
\hline Inclination towards extremism & 0.23 \\
\hline Family characteristics & 0.20 \\
\hline Personal characteristics & 0.40 \\
\hline
\end{tabular}

The slope values confirm that the three variables are naturally distributed. Below are the distribution trends:

Figure No. 1: Natural distribution of the inclination towards extremism variable

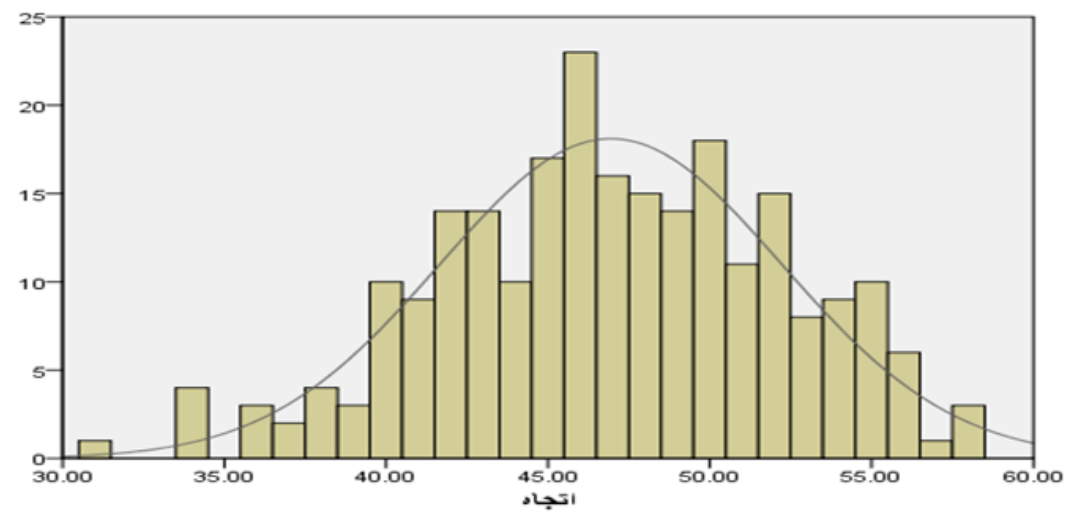

Figure No. 2: Natural distribution of the family characteristics variable 


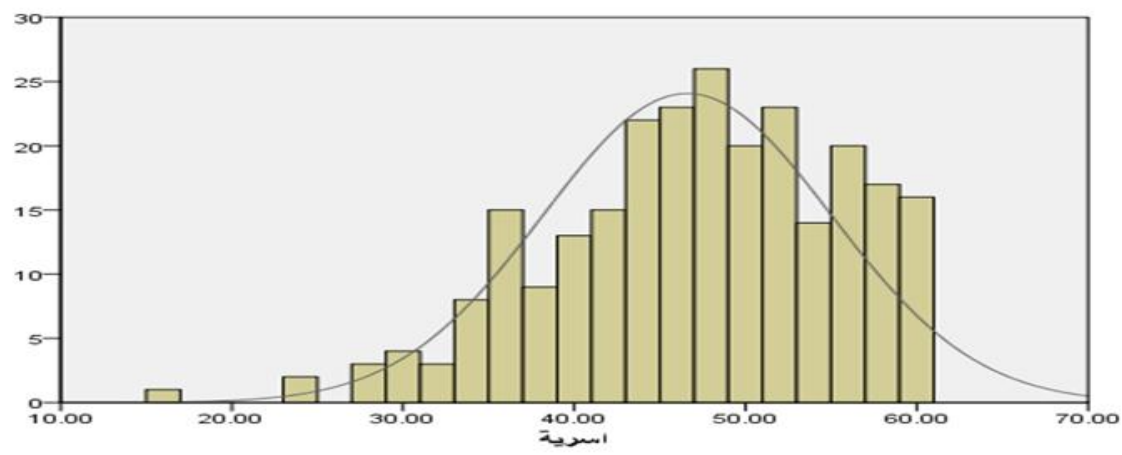

Figure No. 3 Natural distribution of the personal characteristics variable

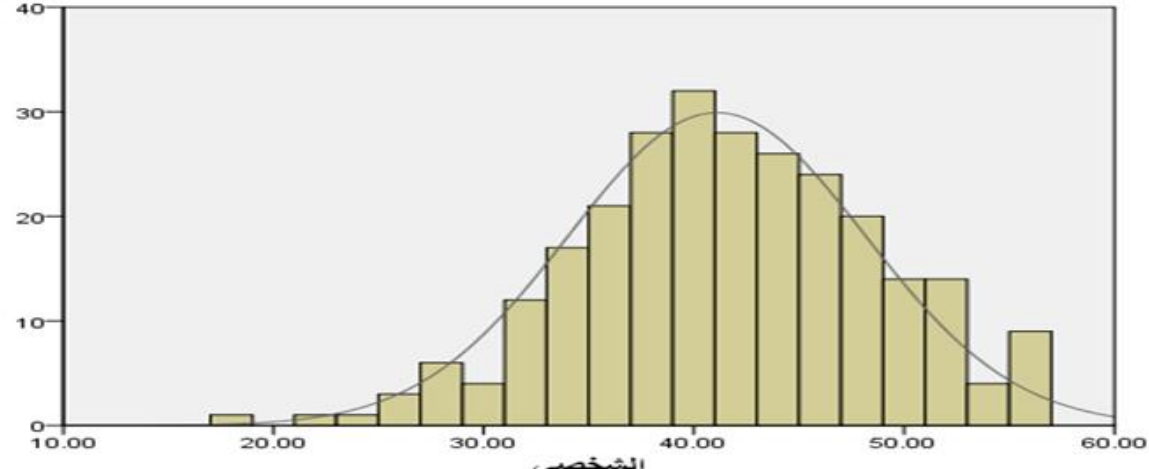

Question 3: is there a correlation between the personal characteristics of the family and the youth's inclination towards extremism?

Table (7) Pearson's Correlation Coefficient of the Personal Characteristics Variable and the Youth's Inclination Towards Extremism

\begin{tabular}{|l|l|l|}
\hline Variables & Pearson's coefficient value & Significance \\
\hline $\begin{array}{l}\text { Personal characteristics and Inclination } \\
\text { towards extremism }\end{array}$ & 0.164 & 0.01 \\
\hline
\end{tabular}

Table(7)indicates that Pearson's correlation coefficient was used in this study to measure the extent to which personal characteristics of the youth and their inclination towards extremism were correlated. The coefficient value is a high score of 0.164, which indicates that there is a significant correlation between the personal characteristics of young people and the students' inclination towards extremism.

Question 4: Is there a correlation between the family characteristics of the youth and their inclination towards extremism?

Table (8) Pearson's Correlation Coefficient of the Family Characteristics Variable and the Youth's Inclination towards Extremism

\begin{tabular}{|l|l|l|}
\hline Variables & Pearson's coefficient value & Significance \\
\hline $\begin{array}{l}\text { Family characteristics and the inclination } \\
\text { towards extremism }\end{array}$ & 0.09 & 0.179 \\
\hline
\end{tabular}

Table (8) shows that there is no correlation between the family characteristics of the youth and their inclination towards extremism, where the results showed that there is no significance (0.179). This is expected because the previous results concerning the correlation between the demographic characteristics of the father and the mother and the youth's inclination towards extremism showed no strong effect between them, which is what the results of this table confirm. 


\section{Discussion}

This study aimed to identify the relationship between the personal and family characteristics of the Saudi youth and the inclination towards extremism, and it was applied to male and female students of King Saud University in the humanities and science faculties through a questionnaire that was distributed to them. The results of the study analysis indicate that there is no statistically significant effect of the independent variable (youth's inclination towards extremism) on the dependent variable (demographic characteristics of the father, and demographic characteristics of the mother), with a level of significance of 0.769 . This indicates that the demographic characteristics of the father and the mother have no effect on the youth's inclination towards extremism. As for the relationship between the personal characteristics and the youth's inclination towards extremism. Results showed that there is a significant correlation, with a high degree of morale at 0.01 . This result confirms the significance of personal characteristics in the youth's inclination towards extremism. As for the relationship between family characteristics and the youth's inclination towards extremism, results indicated that there is no correlation between the youth's family characteristics and their inclination towards extremism, where there is no significance (0.179). This was expected because previous results regarding the relationship between demographic characteristics of the parents and the youth's inclination towards extremism showed no strong influence between the two.

\section{Recommendations}

The researcher concluded with a number of recommendations summarized as follows:

-Providing employment opportunities for the youth, as well as providing them with a socially healthy environment.

-The family, which is the most powerful institution of socialization to influence children, must be more concerned with their children and dialogue in a manner of tolerance, understanding, empathy, and guidance, and qualify them to face life problems with a rational and realistic approach.

-There should be a cultivation of noble values and proper religious guidance based on tolerance and love as one of the most important roles of other institutions of education such as the mosque, university, school, and media.

-Encouraging young people to engage in social, sport, and cultural activities to express their feelings, ideas, and hopes without fanaticism or extremism.

-The need to deal with globalization clearly, comprehensively, and logically, and not to ignore or avoid it; lest it eventually causes social alienation among the youth. Rather, it should be benefited from while preserving our Islamic Arab identity and adhering to our cultural heritage.

* This is a research project that was supported by a grant from the Research Center for the Humanities, Deanship of Scientific Research at King Saud University, 2019.

\section{References}

Abedalaziz N., Jamal Uddin Sh. \&Leng,C. (2013). Measuring Attitudes toward Computer and Internet Usage among Postgraduate Students in Malaysia, Journal of Educational Technology, 12 (2), 200-217 p.

Abu Al Ela, T.(2010).Community Service in the field of Terrorism. Alexandria, Modern University office.

Al Dakheel, A.(2006).Glossary of social services and social sciences. Amman, Daar Al Manahej for publishing and distribution.

Al Dhahian, S.\& Al Sabti, Kh.(2017). Facilitated research methods. Riyadh:IbnRushd publishing house.

Al Mushawah, Saad Abdullah (2007): Psychological factors of the Terrorism Phenomenon, a worksheet presented to an educational symposium "Future of Terrorist Threats" in Riyadh. Center for Studies and Research, Naif Arab University for Security Sciences.

Al Rameeh, Y.(2015).The Role of preventing domestic violence in the fightagainst terrorism. Retrieved from :https://repository.nauss.edu.sa/bitstream/handle/123456789/63539.in Oct.23 ${ }^{\mathrm{rd}} 2018$.

Al Sayyed, A.(1990).Conflict of Generations: a psychological study in the youth culture. Alexandria:Daar Al Marifa Al Jameia.

Al Shahraani, N.(2006). The Role of the University in combating terrorism: a field study applied to faculty members at King Saud University in Riyadh. Unpublished masters thesis, Faculty of Education. King Saud University, Riyadh.

Al Yousef, A.(2005). The role of schools in combating terrorism. A research presented at the World Conference on the position of Islam on Terrorism. Imam Mohammad bin Saud Islamic University.

Al Zghool, I.(2003).Learning Theories. Amman:Daar Al Shurooq.

Allport, G. (1961). Pattern and growth in personality. New York Holt:Rain Hart and Winston, 28 p.

32 
Atkinson, R., Richard, C., Atkinson, E., Smith, Dary, J. Bem, Barker, L. Robert (2003). The Social Work Dictionary$5^{\text {th }}$. Baltimore, MD: Port City Press, 33-155 p.

Eriskon, E. (1963).Childhood and Society.New York: Norton \& Company Inc. 19-20 p.

Moris, C. (1982). Psychology: An Introduction. Fourth Edition. New Jersey: prentice-Hall, Inc. 11 p.

Mursi, K.(2008).Family and Harmony. Cairo:University Publishing house.

Musa, M.(2004).Intellectual deviance and terrorism. A study presented at the coordination meeting of the directors of the centers of research, criminal justice and crime control about intellectual security organized by Naif University for Security Sciences in Medina.

Najm, I.(2013). The role of community service in protecting students against extremism.Alexandria:Daar Al Rifaa for printing and publishing.

Omar, A.(2008). Glossary of Contemporary Arabic Language. First edition. Cairo:Aalam Al Kotob.

Oar, A.\& Abdul Baqi, D.(1988). Al Munjid in Arabic Language. Cairo, Aalam Al Kotob.

Razouk, A.(1979).Encyclopedia of Psychology II. Beirut:The Arab foundation for studies and publishing.

United Nation (2007).World Youth Report 2007.Department of Economic and Social Affairs.United New York.

Yousef, M.(1995). The political, economic, and social variables associated with the problem of terrorism. Halwan University, the eighth scientific conference of the Faculty of community service.

Zaighoor, M.(1986).Psychology of Intolerance. Published lecture. Cairo: Daar Al Nahda Al Arabiya. 